\title{
Adoptive T cell therapy targeting CD1 and MR1
}

\author{
Tingxi Guo ${ }^{1,2}$, Kenji Chamoto $^{2}$ and Naoto Hirano ${ }^{1,2 *}$ \\ ${ }^{1}$ Department of Immunology, University of Toronto, Toronto, ON, Canada, ${ }^{2}$ Princess Margaret Cancer Centre, University Health \\ Network, Toronto, ON, Canada
}

Adoptive T cell immunotherapy has demonstrated clinically relevant efficacy in treating malignant and infectious diseases. However, much of these therapies have been focused on enhancing, or generating de novo, effector functions of conventional $T$ cells recognizing HLA molecules. Given the heterogeneity of HLA alleles, mismatched patients are ineligible for current HLA-restricted adoptive T cell therapies. CD1 and MR1 are class I-like monomorphic molecules and their restricted $T$ cells possess unique $T$ cell receptor specificity against entirely different classes of antigens. CD1 and MR1 molecules present lipid and vitamin B metabolite antigens, respectively, and offer a new front of targets for T cell therapies. This review will cover the recent progress in the basic research of CD1, MR1, and their restricted T cells that possess translational potential.

\section{OPEN ACCESS}

Edited by:

S. M. Mansour Haeryfar, Western University, Canada

Reviewed by:

Toshinori Nakayama, Chiba University Graduate School of Medicine, Japan

Sid P. Kerkar,

National Institutes of Health, USA

*Correspondence: Naoto Hirano,

Princess Margaret Cancer Centre,

University Health Network, 610 University Avenue, Toronto, ON M5G 2M9, Canada

naoto.hirano@utoronto.ca

Specialty section: This article was submitted to T Cell Biology, a section of the journal Frontiers in Immunology

Received: 23 March 2015 Accepted: 06 May 2015 Published: 20 May 2015

Citation:

Guo T, Chamoto $K$ and Hirano N (2015) Adoptive T cell therapy targeting CD1 and MR1. Front. Immunol. 6:247. doi: 10.3389/fimmu.2015.00247
Keywords: immunotherapy, CD1, MR1, NKT, MAIT, T cell, adoptive cell transfer

\section{Introduction}

Given their central role in numerous diseases, $\mathrm{T}$ cells have become the focus and mediators of many immunotherapies. T cell immunotherapy has had impressive success in treating malignant and infectious diseases. Currently, there are several methods of using $\mathrm{T}$ cells as therapy. T cells are cultured and/or engineered ex vivo and adoptively transferred into the patient, or T cells are directly targeted in vivo by vaccination or biological compounds. Regardless of the approach taken, these immunotherapies generate a de novo $\mathrm{T}$ cell-mediated immune response and/or enhance preexisting functions, which are often suppressed in patients. Adoptive T cell transfer therapy offers unique advantages and has been considerably tested in numerous trials. The modern approach to this method allows the personalization of $\mathrm{T}$ cells through the desired ex vivo activation, expansion, and genetic modification, followed by infusion back into the patient (1). As part of this method, we are able to produce a large number of long-lived memory $\mathrm{T}$ cells with defined functions, which last up to years in the patients after infusion depending on the expansion protocol (2). The T cells can also be genetically engineered to express recombinant $\mathrm{T}$ cell receptors (TCRs) or chimeric antigen receptors (CARs) to specifically target tumor or pathogen-associated antigens. Whereas CARs are only able to target surface molecules, TCRs recognizing peptide antigens presented on HLA are able to target the large repertoire of intracellular antigens.

In the past and current TCR-directed adoptive $\mathrm{T}$ cell transfer therapies, most trials have been focused on conventional T cells restricted to one HLA allele. The human HLA gene locus is vastly varied between individuals (3), and although conventional $\mathrm{T}$ cell therapies have aimed to target common alleles such as HLA-A2, a significant portion of HLA-mismatched patients cannot benefit from this type of treatment. Therefore, the heterogeneity of HLA alleles represents a major barrier to the applicability of current TCR-directed adoptive $\mathrm{T}$ cell therapies. With the recent advancements in the field of CD1, MR1, and their, respectively, restricted T cells, these molecules are becoming attractive targets of immunotherapy. These molecules offer the advantage of being monomorphic 


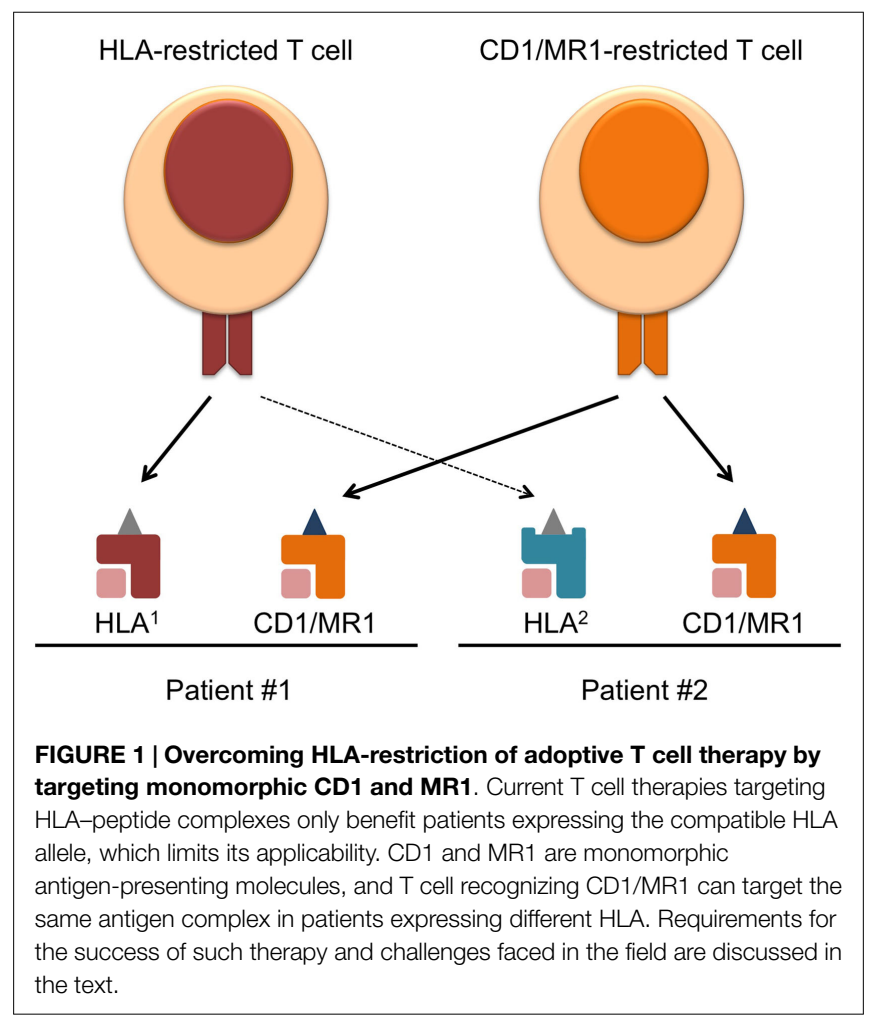

antigen-presenting molecules that are conserved across humans, as well as the ability to present completely different classes of antigens other than peptides (4). Therefore, targeting CD1 and MR1 will broaden the applicability of adoptive T cell therapy (Figure 1).

The MHC class I homolog CD1 family of molecules contains four antigen-presenting members in humans, CD1a-d, and only one in mice, CD1d (5). Many of the CD1 studies have been focused on invariant natural killer T (iNKT) cells (type I NKT) found in both humans and mice. These cells are defined by their invariant TCR $\alpha$ and semi-variant TCR $\beta$ gene usage, and the recognition of the canonical ligand, $\alpha$-galactosylceramide ( $\alpha$-GalCer) (6). The nature of type II NKT cells, which comprise the remainder of CD1d-restricted T cells that do not recognize $\alpha$-GalCer, and $\mathrm{CD} 1 \mathrm{a}-\mathrm{c}$-restricted $\mathrm{T}$ cells have become better understood in recent years. MR1 is also an MHC class I homolog presenting vitamin B metabolites. MR1-antigens complexes are recognized by mucosal-associated invariant T (MAIT) cells, which are another group of evolutionarily conserved $\alpha \beta \mathrm{T}$ cells found in high numbers in humans (7). Like iNKT cells, they express an invariant $\operatorname{TCR} \alpha$ chain that is paired with an oligoclonal TCR $\beta$ chain repertoire (8). These molecules and cognate $\mathrm{T}$ cells will be discussed further in details below.

To date, the only clinical trials involving CD1 and MR1 have been utilizing iNKT cells as a cellular adjuvant by activating them via $\alpha$-GalCer. Many mouse studies implicated roles for iNKT cells in tumor regression (9) and antimicrobial immunity (10). Unfortunately, many of these findings have not been translated well to humans. In the published clinical trials, when cancer or chronically infected patients were treated with iNKT cells activated by $\alpha$-GalCer, alone or pulsed on antigen-presenting cells (APCs), only limited efficacy was observed (11-19). Based on the experiences that led to effective adoptive $\mathrm{T}$ cell therapy targeting HLA, T cell therapies targeting CD1 and MR1 can be improved. In this review, we will address how CD1 and MR1 can be targeted more effectively in diseases by examining the three constituents of successful adoptive $\mathrm{T}$ cell transfer therapy, which are the knowledge of (1) disease-associated target antigen complexes, (2) TCRs that recognize these complexes specifically without eliciting harmful autoimmunity, and (3) the optimal function of the responding T cells.

\section{The Targets}

To target CD1 or MR1 in diseases, their expression on the pathological tissue of interest is necessary. However, the presence of antigen-presenting molecule alone is not enough. An effective T cell therapy should ideally target diseased tissue specifically, with minimal autoimmune response against healthy tissues. Therefore, understanding the nature of antigens presented during pathological and steady state is required to safely and efficiently target CD1 and MR1 in diseases (Table 1).

\section{Pattern of Expression of CD1 and MR1}

The CD1 family of lipid-presenting molecules can be separated based on patterns of expression into two groups. Group 1 includes CD1a, CD1b, and CD1c, and is mainly found on professional APCs and developing thymocytes, with CD1a more strictly restricted to Langerhans cells $(20,25,50)$. Group 2 only includes CD1d and is expressed widely on many tissues $(31,32)$. Similar to CD1d, MR1 is expressed at the transcript level in many tissue types (45), but the detection of surface MR1 expression has been challenging. A newly developed $\mathrm{mAb}$ against murine MR1 was able to stabilize and enhance its transient surface expression (51). However, the MR1 surface expression pattern on human healthy and pathological tissues is largely unknown.

All CD1 molecules can be found on various leukemia and lymphomas, although the exact expression pattern varies between patients $(29,52,53)$. In addition, CD1d can be found on subsets of medulloblastoma, multiple myeloma, and renal cell carcinoma patients (54-56). Other cells in the tumor microenvironment that suppress anti-tumor immunity and/or promote tumor growth also express CD1 molecules. For example, tumor-associated monocytes and macrophages, which are associated with poor prognosis in neuroblastoma patients, were found to express CD1d and could be targeted by iNKT cells in a mouse model (57). Targeting CD1d on both the tumor cells and the supporting stromal cells could be an effective approach.

In infections, CD1d expression can be downregulated by viral immune evasion mechanisms of human immunodeficiency virus and herpes simplex virus $(58,59)$. Similar to MHC class I, surface CD1d expression on epithelial and immune cells is upregulated in inflammatory conditions and can be induced by interferons (60). Yakimchuk et al. recently demonstrated that CD1b and CD1c molecules are upregulated on Langerhans cells of Lyme disease patients compared to healthy samples. In vitro, all group $1 \mathrm{CD} 1$ molecules on monocytes could be upregulated by stimulation with extracted Borrelia burgdorferi lipids via TLR-2 as well as IL$1 \beta$ (61). The expression of CD1 and MR1 molecules need to be 
TABLE 1 | Characteristics of CD1 and MR1 antigen-presenting molecules and their, respectively, restricted T cells in humans

\begin{tabular}{|c|c|c|c|c|}
\hline $\begin{array}{l}\text { Antigen-presenting } \\
\text { molecule }\end{array}$ & Pattern of surface expression & Nature of antigens presented & Cognate TCRs & Frequency of cognate T cells \\
\hline CD1a & $\begin{array}{l}\text { Restricted [thymocytes, professional } \\
\text { APCs, Langerhans cells, Ref. (20)] }\end{array}$ & $\begin{array}{l}\text { Mycobacterial lipopeptide, and } \\
\text { self apolar lipids }(21,22)\end{array}$ & Diverse TCRs & $\begin{array}{l}\sim \text { Up to } 20 \% \text { of } \mathrm{CD}^{+} \text {and } \\
\text { CD4 }^{-} \text {CD }^{-} \text {T cells }(23,24)\end{array}$ \\
\hline CD1b & $\begin{array}{l}\text { Restricted [thymocytes, professional } \\
\text { APCs, Ref. (25)] }\end{array}$ & Mycobacterial lipids $(26,27)$ & $\begin{array}{l}\text { GEM [TRAV1-2-TRAJ9, } \\
\text { Ref. (28)], and diverse TCRs }\end{array}$ & $\begin{array}{l}\sim \text { Up to } 1.5 \% \text { of } \mathrm{CD}^{+}{ }^{+} \text {and } \\
\mathrm{CD}^{-}{ }^{-} \mathrm{CD} 8^{-}-\mathrm{T} \text { cells }(23)\end{array}$ \\
\hline CD1c & $\begin{array}{l}\text { Restricted [thymocytes, professional } \\
\text { APCs, Ref. (25)] }\end{array}$ & $\begin{array}{l}\text { Mycobacterial lipids and self } \\
\text { lysophospholipid }(29,30)\end{array}$ & Diverse TCRs & $\begin{array}{l}\sim \text { Up to } 7 \% \text { of } \mathrm{CD}^{+} \text {and } \\
\mathrm{CD} 4^{-} \mathrm{CD}^{-}-\mathrm{T} \text { cells }(23)\end{array}$ \\
\hline CD1d & $\begin{array}{l}\text { Widely expressed [e.g., } \\
\text { hematopoietic, gastrointestinal, and } \\
\text { reproductive tissues, Ref. }(31,32)]\end{array}$ & $\begin{array}{l}\text { Bacterial and self glycolipids, } \\
\text { plasmalogens, phospholipids } \\
(33-44)\end{array}$ & $\begin{array}{l}\text { iNKT (mostly TRAV10- } \\
\text { TRAJ18 paired with TRBV25), } \\
\text { and diverse TCRs (38) }\end{array}$ & $\begin{array}{l}\sim \text { Up to } 3 \% \text { of } \mathrm{CD}^{+} \text {and } \\
\mathrm{CD} 4^{-} \mathrm{CD}^{-}-\mathrm{T} \text { cells }(23)\end{array}$ \\
\hline MR1 & $\begin{array}{l}\text { Unknown [widely expressed at the } \\
\text { mRNA level, Ref. (45)] }\end{array}$ & $\begin{array}{l}\text { Small molecule metabolites ( } 46 \text {, } \\
47)\end{array}$ & $\begin{array}{l}\text { TRAV1-2 paired with TRBV20 } \\
\text { or TRBV6 TCRs (48) }\end{array}$ & $\sim 1-10 \%$ of total T cells $(48,49)$ \\
\hline
\end{tabular}

Antigens listed only include those that have been identified and validated. Frequency is among peripheral blood T cells in healthy humans.

better characterized for different diseases, since understanding the surface expression pattern on infected or transformed cells in vivo is essential for CD1- or MR1-restricted immunotherapy.

\section{Antigens Presented by CD1 and MR1}

Several studies have shed light on the disease associated and natural antigens presented by CD1 molecules. The ability of group $1 \mathrm{CD} 1$ molecules to present foreign mycobacterial antigens, such as dideoxymycobactin, glucose monomycolate, and mycolic acids, has been well established $(21,26,27,30)$. These antigens are uniquely derived from the bacteria and are not found in the absence of infection. Lepore et al. discovered a novel tumor-associated self-lipid antigen presented by CD1c. Methyllysophosphatidic acid was found 100-fold higher in acute B lymphoblastic leukemia and acute myeloid leukemia cells compared to normal B cells or monocytes, and stimulated T cells in a CD1cdependent manner (29). Although this lipid was also found at elevated levels in dendritic cells, it nevertheless demonstrated the existence of tumor-associated lipid antigens. In addition, some studies have characterized changes in the lipidome of transformed cells $(62,63)$. Therefore, it is likely that more tumor-associated lipid antigens exist and possibly shared across different patients and cancers. The nature of antigenic self-lipids presented by CD1a were also recently elucidated by de Jong et al. Using a CD1arestricted $\mathrm{T}$ cell line, the group showed that apolar lipids lacking hydrophilic functional groups such as squalene and triacylglyceride were antigenic when presented by CD1a (22).

CD1d is able to present several microbial derived $\alpha$-linked glycolipids, which are potent activators of iNKT cells $(33,34)$. For virus-derived lipid antigens, none have been identified to date. However, Zeissig et al. demonstrated that hepatitis B virusinfected human hepatocytes stimulated iNKT cell lines significantly more than non-infected, and this was attributed to the enrichment of virus-induced endogenous antigenic lysophospholipids $(35,36)$. Several new stimulatory lipid ligands recognized by type II NKT cells have also been discovered. Tatituri et al. demonstrated that bacterial and mammalian phosphatidylglycerol and diphosphatidylglycerol were able to stimulate murine type II NKT hybridomas, but not iNKT cells (37). Nair et al. identified $\beta$-glucosylceramide and glucosylsphingosine lysoglucocerebroside as antigens for human and mouse type II NKT cells. The circulating levels of these two lipids are elevated in patients with Gaucher's disease. The group stained PBMC with CD1d tetramer loaded with either of the two lipids, and found that the tetramer positive cells did not express the invariant NKT TCR, indicating that they were not type I iNKT cells. Their frequencies were, in fact, much higher than $\alpha$-GalCer tetramer positive cells. Monocyte-derived DCs pulsed with each antigen were able to expand the respective tetramer positive population (38), validating their stimulatory capacity for type II NKT cells.

In terms of steady state self-lipid antigens, iNKT cells recognize phospholipids, plasmalogens, and glycolipids (39-41). Until recently, it was thought that endogenous mammalian and foreign bacterial glycolipids differed in the $\beta$ or $\alpha$ linkage between the sugar moiety and the lipid. This was due to the fact that mammals lack the enzyme required to form $\alpha$-linked glycolipids, which allowed iNKT cells strongly recognizing $\alpha$-linked glycolipids to easily distinguish between self and foreign antigens. However, two independent groups have reported that a previously identified endogenous $\beta$-linked glycolipid, $\beta$-glucopyranosyl ceramide (42), was contaminated with the rare, but strongly stimulatory $\alpha$-linked version $(43,44)$. Kain et al. demonstrated using $\alpha$-linked glycolipid specific antibody that mammalian cells likely produced this class of lipids (44). These findings strongly influence the choice of antigen for CD1d targeted therapy, since the previously assumed structural exclusivity of foreign and self-glycolipids may not be so strict.

Mucosal-associated invariant $\mathrm{T}$ cells are activated by bacteria but the nature of microbial antigens presented by MR1 remained elusive until recently. Kjer-Nielsen et al. demonstrated vitamin $B$ metabolites as putative ligands presented by MR1, and solved the $\mathrm{x}$-ray crystal structure of a folic acid derivative (6-FP) complexed with MR1. This study also showed that, although 6-FP was not immunogenic in stimulating MAIT TCR transfectants in vitro, a riboflavin-derivative isolated from the supernatant of Salmonella culture was able to upregulate MR1 expression on an MR1-expressing target cell line and activate primary human MAIT cells (46). The same group also identified byproducts of an intermediate of the riboflavin synthesis pathway as MAIT antigens (47). Given the strong influence of gut microbiota on MAIT cells (64), addressing whether these identified antigens are 
presented only during infection or also at steady state dictates their therapeutic potential.

\section{The Receptors}

The responsible molecule that targets CD1 or MR1 is the TCR. Clinical trials have confirmed that $\mathrm{T}$ cells engineered to express a recombinant TCR can effectively target cells expressing cognate antigens in humans. Therefore, understanding the repertoire of CD1 and MR1-restricted TCRs (Table 1) and their molecular mechanism of antigen recognition are important for developing therapy directed at the molecule of interest.

\section{CD1- and MR1-Restricted Invariant $T$ cell Receptors}

Invariant NKT TCRs are the CD1-restricted TCRs that have been most extensively characterized. In humans, iNKT TCRs are largely composed of the TRAV10-TRAJ18 invariant TCR $\alpha$ chain paired with TRBV25 TCR $\beta$ chains with a hypervariable CDR3 $\beta$ region. In mice, they are mainly TRAV11-TRAJ18 TCR $\alpha$ paired with TRBV13, 29, or 1 TCR $\beta$ chains (4). Non-TRAV10 and nonTRAV11 iNKT cells have also been identified in humans and mice, respectively, but are generally rare $(65,66)$. As mentioned above, successful $\mathrm{T}$ cell therapy relies on maximizing on-target effect, while minimizing off-target autoreactivity. Having diseasespecific antigen is only half of the requirement, since antigenspecific receptors are also required to distinguish them from normal tissue antigens. Several studies demonstrated that iNKT TCRs act as pattern-recognition receptors, unable to distinguish the lipid antigen presented by CD1d (67-69). This is attributed to its conserved docking mode on CD1d, where only the germlineencoded regions of the TCR are involved in recognizing the lipid antigen, while the single variable region, CDR3 $\beta$, interacts with the antigen-presenting molecule $(67,68,70)$. Therefore, the diversity in the TCR is supposed to only impact the overall affinity to the lipid-CD1d complex, but not antigen selectivity. This would prevent the isolation of tumor or pathogen-specific iNKT TCR. However, our group has recently characterized a large panel of natural human iNKT TCRs and demonstrated selective antigen recognition of different lipid-CD1d complexes. Furthermore, it appears that most of the peripheral human iNKT cells express antigen-selective TCRs (in revision, Chamoto et al.). Given the many crystal structures of iNKT TCR-CD1d complexes showing the same docking mode, these newly identified human iNKT TCRs unlikely possess an alternate docking mode. It is possible that the hypervariable CDR3 $\beta$ adjust the conformation of the antigen-recognizing germline portion of the TCR (71), in a sequence-dependent manner, thus allowing for distinction between antigens. Intriguingly, mouse and human iNKT TCRs possess cross-species reactivity for human and mouse CD1d, respectively (72). It remains to be seen whether mouse iNKT TCRs are able to distinguish lipid antigens presented by human CD1d. HLA-restricted mouse TCRs have been already tested in the clinic without causing any toxic xenoreaction in cancer patients (73).

Two other subsets of T cells expressing an invariant TCR $\alpha$ chain have been characterized. Recently identified germlineencoded, mycolyl lipid-reactive (GEM) T cells are a subset of
CD1b-restricted T cells expressing a TRAV1-2-TRAJ9 TCR $\alpha$ chain. These TCRs possess a fixed CDR $3 \alpha$ length and minor amino acid variations across different tuberculosis patients. Clonotypic GEM TCRs recognized either mycobacterial antigen glucose monomycolate or mycolic acid presented by CD1b. Structural analysis demonstrated that the footprint of GEM TCRs on CD1b-antigens resembled conventional TCRs, which explains their ability to distinguish the two antigens. Furthermore, GEM TCRs recognized foreign antigens with high affinity and did not display baseline autoreactivity (28). Thus, they represent a viable option in targeting these mycobacteria-derived antigens.

Mucosal-associated invariant $\mathrm{T}$ cells represent the third group of $\mathrm{T}$ cells with a biased TCR repertoire. Recently developed MR1 tetramer loaded with the stimulatory riboflavin-derivative demonstrated that MAIT TCRs also utilize the TRAV1-2 gene, which is mostly rearranged to TRAJ33, and pairing mostly with TRBV20 or TRBV6-4 (48). Functional and structural studies on MAIT TCRs suggested that they possess antigen selectivity, where stimulation by $\mathrm{MR}^{+}$target cells infected by different genus of microbes specifically enriched different clonal populations of MAIT cells ex vivo (74). This is consistent with the crystal structures of MAIT TCR-MR1-antigen complexes, where the TCR takes a more perpendicular docking mode similar to GEM and conventional TCRs $(75,76)$. In these studies, no interactions were identified between the hypervariable CDR3 $\beta$ of the MAIT TCR and the two vitamin B metabolite antigens previously identified. Interestingly, however, this docking mode permitted the hypervariable region of the MAIT TCR to interact with novel antigens (47) and a derivative of 6-FP presented by MR1 (77). In the two subsequent studies, the crystal structures of several MAIT TCRs-MR1-antigen complexes were solved, showing that the CDR3 $\beta$ loop directly interacted with the antigen. Collectively, these evidences support an antigen-selective mode of recognition by MAIT TCRs.

\section{CD1-Restricted Diverse T Cell Receptors}

Non-invariant TCRs recognizing CD1 represent the majority of the total CD1-restricted TCR repertoire in humans $(23,38)$. These diverse TCRs do not appear to possess the conserved parallel docking mode seen with iNKT TCRs. The crystal structures of murine type II NKT TCRs recognizing CD1d-self-antigens demonstrated an orthogonal docking mode similar to the one classically seen with MHC-restricted TCR $(78,79)$. The CDR3 $\beta$ made direct interactions with the antigens, indicating that type II NKT TCRs, if all similarly possess this docking mode, would potentially be able to discriminate antigens depending on the hypervariable CDR3 sequences. Roy et al. performed alanine scanning on the CD1c molecule presenting mycobacterial phosphomycoketide (PM) and measured the dissociation constant for the mutants against a panel of CD1c-PM reactive clones (80). The group observed that different point mutations affected the strength of interaction differently for different TCRs. This would not be expected if all the TCRs recognized the CD1c complex in a conserved manner. Whether this variable docking mode holds true for $\mathrm{CD} 1 \mathrm{c}$ presenting other foreign and self-antigens remains to be tested, and examining the antigen selectivity of this unpredictable docking mode requires experiments involving 
more antigens. The crystal structure of TCR-CD1a-self ligand was recently solved with a clonotypic CD1a-restricted TCR. In this study, although the TCR docked orthogonally onto CD1a, the recognition of the antigen complex relied on contacts with $\mathrm{CD} 1 \mathrm{a}$ only. This allowed the TCR to recognize various "permissive" selfligands that did not disrupt the TCR-CD1a interaction (81). It will be of interest to see if this is also the case with other CD1arestricted TCRs. How diverse CD1b-restricted TCRs recognize the cognate CD1-antigen complex and their ligand selectivity remains uncharacterized. CD1c- and CD1d-restricted $\gamma \delta$ TCRs have also been identified (82-84), and offer a separate repertoire from which to isolate disease-specific receptors. Structural analysis demonstrated that CD1d-restricted $\gamma \delta$ TCRs recognized the antigen complex also similarly to conventional MHC-restricted TCRs (85). The germline-encoded CDR1 and CDR2 recognized the monomorphic CD1d, while the hypervariable CDR3 $\delta$ was positioned on top of the ligand. This is highly suggestive of an antigen-selective mode of recognition. The wealth of potentially antigen-selective $\alpha \beta$ and $\gamma \delta$ TCRs recognizing CD1- or MR1antigen complexes hold great therapeutic potential for cancer and infection-specific T cell therapy restricted by CD1 or MR1.

\section{The Cells}

\section{Functional Phenotype of CD1- and MR1-Restricted T Cells}

In the cases of cancer and infection, the ultimate goal of immunotherapy is to induce cell death in the malignant or infected cells to control the disease. As mentioned above, iNKT cells have been targeted with the aim to jump-start the ensuing immune response that ultimately leads to a cytotoxic cellular response. However, in mice, multiple functional subsets of iNKT cells paralleling MHC class II-restricted T cells have been discovered. Lee et al. identified NKT1, NKT2, and NKT17 subsets that preferentially secrete IFN- $\gamma$, IL-4, and IL-17, respectively, based on the lineage transcription factor expressed (86). It is unknown whether the NKT1, NKT2, and NKT17 functional subsets exist in humans, and if so, the variation in the frequency of the different functional lineages between individuals needs to be addressed. A small fraction of suppressive IL-10 secreting iNKT cells was reported in humans, and their frequency in peripheral blood ranged over one order of magnitude between individuals (87). Activation of one or a few particular functional subsets of iNKT cells by $\alpha$-GalCer in some of the clinical trials might explain the lack of efficacy, especially if the activated subset antagonizes a favorable response. As for the other CD1-restricted T cells and MR1-restricted MAIT cells, their functions in vivo are largely unknown but likely resemble Th1 and/or Th17 phenotypes. Ex vivo or in vitro stimulation studies demonstrated that non-iNKT CD1-restricted T cells are capable of producing IFN- $\gamma$ and MAIT cells producing both IFN- $\gamma$ and IL-17, both with some capacity for cytotoxicity and IL-2 production $(22,23,28,61,74,88-90)$. CD1a-restricted $\mathrm{T}$ cells are also able to produce IL-22, consistent with their role in dermal immunity (24). Nevertheless, the fidelity of much of these functions in vivo remains to be examined before CD1-restricted T cells and MAIT cells can be used to combat the appropriate disease. Although a Th1 functional profile is generally preferred for optimal anti-tumor and viral immunity, the multifaceted functionality of CD1- and MR1-restricted T cells can potentially expand their applicability to other diseases.

\section{Large Scale Production of Effector Cells}

Once the function of these cells has been established, other aspects of making adoptive therapy successful need to be considered. Obtaining a large number of effector cells is important for efficacy. For example, typically 10-100 billion HLA-restricted T cells are infused to a single cancer patient, although not all are antigenspecific, it still represents a sizable number. Depending on the type of function and the aim of the therapy, fewer cells could be required. Nevertheless, given the limited number of iNKT cells in the periphery, it will be necessary to expand this population for therapy. $\alpha$-GalCer-based stimulation has been traditionally used and serves as an effective method to expand iNKT cells, either pulsed on APCs or in a cell-free system. However, this method expands all iNKT cells independent of antigen selectivity, avidity, and functional profile. There is also evidence indicating that $\alpha$-GalCer-expanded iNKT cells possess an anergic phenotype (91). Although other CD1-restricted T cells and MAIT cells are more numerous in the peripheral blood $(23,24,48,49)$, they will likely also require ex vivo expansion for therapeutic use (Table 1). Cell-based artificial antigen-presenting cells (aAPCs) have been highly effective in expanding conventional MHC-restricted $\mathrm{T}$ cells in preclinical and clinical settings (2, 92-94). Similar aAPCs expressing different CD1 molecules have been developed and could stimulate, respectively, restricted $\mathrm{T}$ cells (24). It is possible to improve the capacity of these aAPCs to expand and stimulate CD1 or MR1-restricted T cells by co-expressing the necessary costimulatory molecules along with CD1 or MR1, and culturing in the appropriate cytokine milieu (92).

\section{Memory and Longevity}

The longevity of infused $\mathrm{T}$ cells in vivo is also an important factor in clinical success. It has been demonstrated that central memory $\mathrm{T}$ cells are more effective than terminally differentiated $\mathrm{T}$ cells in adoptive $\mathrm{T}$ cell models of cancer and chronic viral infection, owing to their prolonged survival and effector output (95). iNKT cells are well-known for their pre-primed effector memory phenotype, immediate after maturation and in the absence of antigen exposure, which allows their rapid response. Majority of iNKT cells do not express L-selectin (6), a key marker of naïve and central memory phenotype. Although the in vivo turnover rate of peripheral and adoptively transferred iNKT cells is unknown, their effector memory phenotype does not suggest prolonged persistence to the extent of central memory conventional $\mathrm{T}$ cells. By contrast, a significant portion of type II NKT cells were recently described to possess a naïve-like phenotype, expressing L-selectin and CD45RA (38). This strongly suggests that they could potentially differentiate to long-lived central memory $\mathrm{T}$ cells. In fact, CD1-restricted T cells in general, excluding iNKT cells, seem to possess a naïve $\mathrm{T}$ cell phenotype (23). Likewise, MAIT cells in PBMC express central memory markers and start to demonstrate a memory phenotype as early as the age of 3 months in humans (89). Whether the expression pattern of memory phenotype markers on these unconventional $\mathrm{T}$ cells confer the same cellular longevity as 
conventional MHC-restricted T cells need to be evaluated. Furthermore, the memory phenotype of CD1- and MR1-restricted $\mathrm{T}$ cells can be altered during ex vivo expansion, as seen with conventional T cells, where they lose their survival capacity after repeated stimulation and subsequent expansion (96). The aAPC system developed can be a useful tool to expand these cells, while maintaining the desired memory phenotype $(2,97)$.

\section{Mix and Match - Building the Best Therapy}

In the age of genetic engineering reaching ever higher levels of feasibility and safety, cellular immunotherapies are no longer limited by the inherent constraints of the naturally existing immune system. The aforementioned problems of iNKT cells in therapy (e.g., apparent lack of antigen and functional specificity, and shortage of numbers) can be overcome by extrinsically modifying cell-intrinsic properties. Heczey et al. recently demonstrated that introducing a CAR targeting GD2, a tumor-associated surface ganglioside, to sorted and expanded human iNKT cells can redirect their specificity independent of CD1d. Importantly, the CAR contained the 4-1BB signaling domain and biased the iNKT cells to a Th1 phenotype upon antigen engagement (98). This approach is an example of how to overcome the inherent limitations of iNKT cells. Conversely, CD1 and MR1 can be targeted by redirecting conventional MHC-restricted T cells with TCRs recognizing CD1/MR1-antigen complexes of interest. This would be one of the most practical and translatable methods of targeting CD1 and MR1 currently, since transducing $\mathrm{T}$ cells with recombinant TCRs is a fairly well-established methodology to redirect $\mathrm{T}$ cell reactivity and has been used in many trials (99). The major barrier to this would be to identify the appropriate TCRs capable of selectively recognizing diseased tissues, as discussed above, which will represent the rate-limiting step to target CD1 and MR1 through conventional $\mathrm{T}$ cells. Combining cell-based therapy targeting CD1 and MR1 with small-molecules (100), checkpoint blockade

\section{References}

1. Maus MV, Fraietta JA, Levine BL, Kalos M, Zhao Y, June CH. Adoptive immunotherapy for cancer or viruses. Annu Rev Immunol (2014) 32:189-225. doi:10.1146/annurev-immunol-032713-120136

2. Butler MO, Friedlander P, Milstein MI, Mooney MM, Metzler G, Murray AP, et al. Establishment of antitumor memory in humans using in vitro-educated CD8+ T cells. Sci Transl Med (2011) 3(80):80ra34. doi:10.1126/scitranslmed. 3002207

3. Mungall AJ, Palmer SA, Sims SK, Edwards CA, Ashurst JL, Wilming L, et al. The DNA sequence and analysis of human chromosome 6. Nature (2003) 425(6960):805-11. doi:10.1038/nature02055

4. Salio M, Silk JD, Jones EY, Cerundolo V. Biology of CD1- and MR1restricted T cells. Annu Rev Immunol (2014) 32:323-66. doi:10.1146/ annurev-immunol-032713-120243

5. Adams EJ. Lipid presentation by human CD1 molecules and the diverse T cell populations that respond to them. Curr Opin Immunol (2014) 26:1-6. doi:10.1016/j.coi.2013.09.005

6. Matsuda JL, Mallevaey T, Scott-Browne J, Gapin L. CD1d-restricted iNKT cells, the 'Swiss-Army knife' of the immune system. Curr Opin Immunol (2008) 20(3):358-68. doi:10.1016/j.coi.2008.03.018

7. Birkinshaw RW, Kjer-Nielsen L, Eckle SB, McCluskey J, Rossjohn J. MAITs, MR1 and vitamin B metabolites. Curr Opin Immunol (2014) 26:7-13. doi:10. 1016/j.coi.2013.09.007 reagents, or other biologics could also prove to be beneficial. AntiCTLA4 mAb treatment combined with adoptive HLA-restricted T cell therapy indeed demonstrated greater efficacy than adoptive $\mathrm{T}$ cell therapy alone (2). Lastly, CD1, MR1, or MHC-presented antigens, if they are expressed simultaneously or in combinations on the target cells, can be targeted together to minimize the immune escape routes of the malignant or infectious agents, since these three classes of antigen-presenting molecules likely present ligands derived from non-overlapping molecular pathways.

\section{Concluding Remarks}

Adoptive cell therapy of MHC-restricted T cells has undoubtedly produced impressive clinical responses in chronically infected and cancer patients. Use of $\mathrm{T}$ cells targeting lipids and small molecule metabolites presented by CD1 and MR1 as a T cell graft will broaden applicability of T cell therapy to more diseases and patients without the limitation of HLA restriction. The research areas pivotal for successful adoptive CD1- and MR1-restricted T cell therapy, which are already underway, are to better characterize the pattern of expression of CD1 and MR1 molecules, identify disease-associated antigens processed and presented by CD1 and MR1 molecules, and isolate cognate TCRs or T cells with the desired function that recognize these antigen complexes but not others. Although the biology of CD1- and MR1-restricted T cells and their receptors require further study before being tested in clinical trials, they represent an exciting venue of therapeutic potential in the near future.

\section{Acknowledgments}

This work was supported by NIH Grant (R01 CA148673), Princess Margaret Foundation, Ontario Institute for Cancer Research (Clinical Investigator Award IA-39), Canadian Institutes of Health Research, Government of Ontario, and University of Toronto.

8. Lepore M, Kalinichenko A, Colone A, Paleja B, Singhal A, Tschumi A, et al. Parallel T-cell cloning and deep sequencing of human MAIT cells reveal stable oligoclonal TCRbeta repertoire. Nat Commun (2014) 5:3866. doi:10.1038/ ncomms 4866

9. Swann JB, Smyth MJ. Immune surveillance of tumors. J Clin Invest (2007) 117(5):1137-46. doi:10.1172/JCI31405

10. Tupin E, Kinjo Y, Kronenberg M. The unique role of natural killer T cells in the response to microorganisms. Nat Rev Microbiol (2007) 5(6):405-17. doi:10.1038/nrmicro1657

11. Giaccone G, Punt CJ, Ando Y, Ruijter R, Nishi N, Peters M, et al. A phase I study of the natural killer T-cell ligand alpha-galactosylceramide (KRN7000) in patients with solid tumors. Clin Cancer Res (2002) 8(12):3702-9.

12. Ishikawa A, Motohashi S, Ishikawa E, Fuchida H, Higashino K, Otsuji M, et al. A phase I study of alpha-galactosylceramide (KRN7000)-pulsed dendritic cells in patients with advanced and recurrent non-small cell lung cancer. Clin Cancer Res (2005) 11(5):1910-7. doi:10.1158/1078-0432.CCR-04-1453

13. Motohashi S, Ishikawa A, Ishikawa E, Otsuji M, Iizasa $T$, Hanaoka $H$, et al. A phase I study of in vitro expanded natural killer $\mathrm{T}$ cells in patients with advanced and recurrent non-small cell lung cancer. Clin Cancer Res (2006) 12(20 Pt 1):6079-86. doi:10.1158/1078-0432.CCR-06-0114

14. Veldt BJ, van der Vliet HJ, von Blomberg BM, van Vlierberghe H, Gerken G, Nishi N, et al. Randomized placebo controlled phase I/II trial of alphagalactosylceramide for the treatment of chronic hepatitis C. J Hepatol (2007) 47(3):356-65. doi:10.1016/j.jhep.2007.04.018 
15. Woltman AM, Ter Borg MJ, Binda RS, Sprengers D, von Blomberg BM, Scheper RJ, et al. Alpha-galactosylceramide in chronic hepatitis B infection: results from a randomized placebo-controlled phase I/II trial. Antivir Ther (2009) 14(6):809-18. doi:10.3851/1295

16. Motohashi S, Nagato K, Kunii N, Yamamoto H, Yamasaki K, Okita K, et al. A phase I-II study of alpha-galactosylceramide-pulsed IL-2/GM-CSF-cultured peripheral blood mononuclear cells in patients with advanced and recurrent non-small cell lung cancer. J Immunol (2009) 182(4):2492-501. doi:10.4049/ jimmunol.0800126

17. Uchida T, Horiguchi S, Tanaka Y, Yamamoto H, Kunii N, Motohashi S, et al. Phase I study of alpha-galactosylceramide-pulsed antigen presenting cells administration to the nasal submucosa in unresectable or recurrent head and neck cancer. Cancer Immunol Immunother (2008) 57(3):337-45. doi:10.1007/ s00262-007-0373-5

18. Kunii N, Horiguchi S, Motohashi S, Yamamoto H, Ueno N, Yamamoto S, et al. Combination therapy of in vitro-expanded natural killer $\mathrm{T}$ cells and alphagalactosylceramide-pulsed antigen-presenting cells in patients with recurrent head and neck carcinoma. Cancer Sci (2009) 100(6):1092-8. doi:10.1111/j. 1349-7006.2009.01135.x

19. Yamasaki K, Horiguchi S, Kurosaki M, Kunii N, Nagato K, Hanaoka H, et al. Induction of NKT cell-specific immune responses in cancer tissues after NKT cell-targeted adoptive immunotherapy. Clin Immunol (2011) 138(3):255-65. doi:10.1016/j.clim.2010.11.014

20. Pena-Cruz V, Ito S, Dascher CC, Brenner MB, Sugita M. Epidermal Langerhans cells efficiently mediate CD1a-dependent presentation of microbial lipid antigens to T cells. J Invest Dermatol (2003) 121(3):517-21. doi:10.1046/j. 1523-1747.2003.12429.x

21. Moody DB, Young DC, Cheng TY, Rosat JP, Roura-Mir C, O'Connor PB, et al. $\mathrm{T}$ cell activation by lipopeptide antigens. Science (2004) 303(5657):527-31. doi:10.1126/science. 1089353

22. de Jong A, Cheng TY, Huang S, Gras S, Birkinshaw RW, Kasmar AG, et al. CD1a-autoreactive $\mathrm{T}$ cells recognize natural skin oils that function as headless antigens. Nat Immunol (2014) 15(2):177-85. doi:10.1038/ni.2790

23. de Lalla C, Lepore M, Piccolo FM, Rinaldi A, Scelfo A, Garavaglia C, et al. High-frequency and adaptive-like dynamics of human CD1 self-reactive $\mathrm{T}$ cells. Eur J Immunol (2011) 41(3):602-10. doi:10.1002/eji.201041211

24. de Jong A, Pena-Cruz V, Cheng TY, Clark RA, Van Rhijn I, Moody DB. CD1aautoreactive $\mathrm{T}$ cells are a normal component of the human alphabeta $\mathrm{T}$ cell repertoire. Nat Immunol (2010) 11(12):1102-9. doi:10.1038/ni.1956

25. McMichael AJ. Leucocyte Typing III: White Cell Differentiation Antigens. Oxford, NY: Oxford University Press (1987). xxxiv,1050 p.

26. Moody DB, Reinhold BB, Guy MR, Beckman EM, Frederique DE, Furlong ST, et al. Structural requirements for glycolipid antigen recognition by CD1brestricted T cells. Science (1997) 278(5336):283-6. doi:10.1126/science.278. 5336.283

27. Beckman EM, Porcelli SA, Morita CT, Behar SM, Furlong ST, Brenner MB. Recognition of a lipid antigen by CD1-restricted alpha beta+ T cells. Nature (1994) 372(6507):691-4. doi:10.1038/372691a0

28. Van Rhijn I, Kasmar A, de Jong A, Gras S, Bhati M, Doorenspleet ME, et al. A conserved human $\mathrm{T}$ cell population targets mycobacterial antigens presented by CD1b. Nat Immunol (2013) 14(7):706-13. doi:10.1038/ni.2630

29. Lepore M, de Lalla C, Gundimeda SR, Gsellinger H, Consonni M, Garavaglia $\mathrm{C}$, et al. A novel self-lipid antigen targets human T cells against CD1c(+) leukemias. J Exp Med (2014) 211(7):1363-77. doi:10.1084/jem.20140410

30. Moody DB, Ulrichs T, Muhlecker W, Young DC, Gurcha SS, Grant E, et al. CD1c-mediated T-cell recognition of isoprenoid glycolipids in Mycobacterium tuberculosis infection. Nature (2000) 404(6780):884-8. doi:10.1038/35009119

31. Canchis PW, Bhan AK, Landau SB, Yang L, Balk SP, Blumberg RS. Tissue distribution of the non-polymorphic major histocompatibility complex class I-like molecule, CD1d. Immunology (1993) 80(4):561-5.

32. Blumberg RS, Terhorst C, Bleicher P, McDermott FV, Allan CH, Landau SB, et al. Expression of a nonpolymorphic MHC class I-like molecule, CD1D, by human intestinal epithelial cells. J Immunol (1991) 147(8):2518-24.

33. Kinjo Y, Illarionov P, Vela JL, Pei B, Girardi E, Li X, et al. Invariant natural killer $\mathrm{T}$ cells recognize glycolipids from pathogenic Gram-positive bacteria. Nat Immunol (2011) 12(10):966-74. doi:10.1038/ni.2096

34. Sriram V, Du W, Gervay-Hague J, Brutkiewicz RR. Cell wall glycosphingolipids of Sphingomonas paucimobilis are CD1d-specific ligands for NKT cells. Eur J Immunol (2005) 35(6):1692-701. doi:10.1002/eji.200526157
35. Zeissig S, Murata K, Sweet L, Publicover J, Hu Z, Kaser A, et al. Hepatitis $\mathrm{B}$ virus-induced lipid alterations contribute to natural killer $\mathrm{T}$ celldependent protective immunity. Nat Med (2012) 18(7):1060-8. doi:10.1038/ nm. 2811

36. Fox LM, Cox DG, Lockridge JL, Wang X, Chen X, Scharf L, et al. Recognition of lyso-phospholipids by human natural killer T lymphocytes. PLoS Biol (2009) 7(10):e1000228. doi:10.1371/journal.pbio.1000228

37. Tatituri RV, Watts GF, Bhowruth V, Barton N, Rothchild A, Hsu FF, et al. Recognition of microbial and mammalian phospholipid antigens by NKT cells with diverse TCRs. Proc Natl Acad Sci U S A (2013) 110(5):1827-32. doi:10.1073/pnas.1220601110

38. Nair S, Boddupalli CS, Verma R, Liu J, Yang R, Pastores GM, et al. Type II NKTTFH cells against Gaucher lipids regulate B cell immunity and inflammation. Blood (2015) 125(8):1256-71. doi:10.1182/blood-2014-09-600270

39. Facciotti F, Ramanjaneyulu GS, Lepore M, Sansano S, Cavallari M, Kistowska $\mathrm{M}$, et al. Peroxisome-derived lipids are self antigens that stimulate invariant natural killer T cells in the thymus. Nat Immunol (2012) 13(5):474-80. doi:10. 1038/ni.2245

40. Zhou D, Mattner J, Cantu C III, Schrantz N, Yin N, Gao Y, et al. Lysosomal glycosphingolipid recognition by NKT cells. Science (2004) 306(5702):1786-9. doi: $10.1126 /$ science. 1103440

41. Cox D, Fox L, Tian R, Bardet W, Skaley M, Mojsilovic D, et al. Determination of cellular lipids bound to human CD1d molecules. PLoS One (2009) 4(5):e5325. doi:10.1371/journal.pone.0005325

42. Brennan PJ, Tatituri RV, Brigl M, Kim EY, Tuli A, Sanderson JP, et al. Invariant natural killer $\mathrm{T}$ cells recognize lipid self antigen induced by microbial danger signals. Nat Immunol (2011) 12(12):1202-11. doi:10.1038/ni.2143

43. Brennan PJ, Tatituri RV, Heiss C, Watts GF, Hsu FF, Veerapen N, et al. Activation of iNKT cells by a distinct constituent of the endogenous glucosylceramide fraction. Proc Natl Acad Sci U S A (2014) 111(37):13433-8. doi:10.1073/pnas.1415357111

44. Kain L, Webb B, Anderson BL, Deng S, Holt M, Constanzo A, et al. The identification of the endogenous ligands of natural killer $\mathrm{T}$ cells reveals the presence of mammalian alpha-linked glycosylceramides. Immunity (2014) 41(4):543-54. doi:10.1016/j.immuni.2014.08.017

45. Riegert P, Wanner V, Bahram S. Genomics, isoforms, expression, and phylogeny of the MHC class I-related MR1 gene. J Immunol (1998) 161(8):4066-77.

46. Kjer-Nielsen L, Patel O, Corbett AJ, Le Nours J, Meehan B, Liu L, et al. MR1 presents microbial vitamin B metabolites to MAIT cells. Nature (2012) 491(7426):717-23. doi:10.1038/nature11605

47. Corbett AJ, Eckle SB, Birkinshaw RW, Liu L, Patel O, Mahony J, et al. Tcell activation by transitory neo-antigens derived from distinct microbial pathways. Nature (2014) 509(7500):361-5. doi:10.1038/nature13160

48. Reantragoon R, Corbett AJ, Sakala IG, Gherardin NA, Furness JB, Chen Z, et al. Antigen-loaded MR1 tetramers define $\mathrm{T}$ cell receptor heterogeneity in mucosal-associated invariant T cells. J Exp Med (2013) 210(11):2305-20. doi:10.1084/jem.20130958

49. Leeansyah E, Loh L, Nixon DF, Sandberg JK. Acquisition of innate-like microbial reactivity in mucosal tissues during human fetal MAIT-cell development. Nat Commun (2014) 5:3143. doi:10.1038/ncomms4143

50. Dougan SK, Kaser A, Blumberg RS. CD1 expression on antigen-presenting cells. Curr Top Microbiol Immunol (2007) 314:113-41.

51. Chua WJ, Kim S, Myers N, Huang S, Yu L, Fremont DH, et al. Endogenous MHC-related protein 1 is transiently expressed on the plasma membrane in a conformation that activates mucosal-associated invariant T cells. J Immunol (2011) 186(8):4744-50. doi:10.4049/jimmunol.1003254

52. Metelitsa LS, Weinberg KI, Emanuel PD, Seeger RC. Expression of CD1d by myelomonocytic leukemias provides a target for cytotoxic NKT cells. Leukemia (2003) 17(6):1068-77. doi:10.1038/sj.leu.2402943

53. Fais F, Tenca C, Cimino G, Coletti V, Zanardi S, Bagnara D, et al. CD1d expression on B-precursor acute lymphoblastic leukemia subsets with poor prognosis. Leukemia (2005) 19(4):551-6. doi:10.1038/sj.leu.2403671

54. Liu D, Song L, Brawley VS, Robison N, Wei J, Gao X, et al. Medulloblastoma expresses CD1d and can be targeted for immunotherapy with NKT cells. Clin Immunol (2013) 149(1):55-64. doi:10.1016/j.clim.2013.06.005

55. Spanoudakis E, Hu M, Naresh K, Terpos E, Melo V, Reid A, et al. Regulation of multiple myeloma survival and progression by CD1d. Blood (2009) 113(11):2498-507. doi:10.1182/blood-2008-06-161281 
56. Chong TW, Goh FY, Sim MY, Huang HH, Thike DA, Lim WK, et al. CD1d expression in renal cell carcinoma is associated with higher relapse rates, poorer cancer-specific and overall survival. J Clin Pathol (2015) 68(3):200-5. doi:10.1136/jclinpath-2014-202735

57. Song L, Asgharzadeh S, Salo J, Engell K, Wu HW, Sposto R, et al. Valpha24-invariant NKT cells mediate antitumor activity via killing of tumorassociated macrophages. J Clin Invest (2009) 119(6):1524-36. doi:10.1172/ JCI37869

58. Hage CA, Kohli LL, Cho S, Brutkiewicz RR, Twigg HL III, Knox KS. Human immunodeficiency virus gp120 downregulates CD1d cell surface expression. Immunol Lett (2005) 98(1):131-5. doi:10.1016/j.imlet.2004.10.025

59. Rao P, Pham HT, Kulkarni A, Yang Y, Liu X, Knipe DM, et al. Herpes simplex virus 1 glycoprotein B and US3 collaborate to inhibit CD1d antigen presentation and NKT cell function. J Virol (2011) 85(16):8093-104. doi:10. 1128/JVI.02689-10

60. Kawana K, Matsumoto J, Miura S, Shen L, Kawana Y, Nagamatsu T, et al. Expression of CD1d and ligand-induced cytokine production are tissue specific in mucosal epithelia of the human lower reproductive tract. Infect Immun (2008) 76(7):3011-8. doi:10.1128/IAI.01672-07

61. Yakimchuk K, Roura-Mir C, Magalhaes KG, de Jong A, Kasmar AG, Granter $\mathrm{SR}$, et al. Borrelia burgdorferi infection regulates CD1 expression in human cells and tissues via IL1-beta. Eur J Immunol (2011) 41(3):694-705. doi:10.1002/eji. 201040808

62. Doria ML, Cotrim CZ, Simoes C, Macedo B, Domingues P, Domingues MR, et al. Lipidomic analysis of phospholipids from human mammary epithelial and breast cancer cell lines. J Cell Physiol (2013) 228(2):457-68. doi:10.1002/ jcp. 24152

63. Fhaner CJ, Liu S, Ji H, Simpson RJ, Reid GE. Comprehensive lipidome profiling of isogenic primary and metastatic colon adenocarcinoma cell lines. Anal Chem (2012) 84(21):8917-26. doi:10.1021/ac302154g

64. Treiner E, Duban L, Bahram S, Radosavljevic M, Wanner V, Tilloy F, et al. Selection of evolutionarily conserved mucosal-associated invariant $\mathrm{T}$ cells by MR1. Nature (2003) 422(6928):164-9. doi:10.1038/nature01433

65. Gadola SD, Dulphy N, Salio M, Cerundolo V. Valpha24-JalphaQ-independent, CD1d-restricted recognition of alpha-galactosylceramide by human CD4(+) and CD8alphabeta(+) T lymphocytes. J Immunol (2002) 168(11):5514-20. doi:10.4049/jimmunol.168.11.5514

66. Uldrich AP, Patel O, Cameron G, Pellicci DG, Day EB, Sullivan LC, et al. A semi-invariant Valpha10+ $\mathrm{T}$ cell antigen receptor defines a population of natural killer T cells with distinct glycolipid antigen-recognition properties. Nat Immunol (2011) 12(7):616-23. doi:10.1038/ni.2051

67. Mallevaey T, Clarke AJ, Scott-Browne JP, Young MH, Roisman LC, Pellicci DG, et al. A molecular basis for NKT cell recognition of CD1d-self-antigen. Immunity (2011) 34(3):315-26. doi:10.1016/j.immuni.2011.01.013

68. Pellicci DG, Clarke AJ, Patel O, Mallevaey T, Beddoe T, Le Nours J, et al. Recognition of beta-linked self glycolipids mediated by natural killer $\mathrm{T}$ cell antigen receptors. Nat Immunol (2011) 12(9):827-33. doi:10.1038/ni.2076

69. Matulis G, Sanderson JP, Lissin NM, Asparuhova MB, Bommineni GR, Schumperli D, et al. Innate-like control of human iNKT cell autoreactivity via the hypervariable CDR3beta loop. PLoS Biol (2010) 8(6):e1000402. doi:10. 1371/journal.pbio.1000402

70. Borg NA, Wun KS, Kjer-Nielsen L, Wilce MC, Pellicci DG, Koh R, et al. CD1dlipid-antigen recognition by the semi-invariant NKT T-cell receptor. Nature (2007) 448(7149):44-9. doi:10.1038/nature05907

71. Lopez-Sagaseta J, Sibener LV, Kung JE, Gumperz J, Adams EJ. Lysophospholipid presentation by CD1d and recognition by a human natural killer T-cell receptor. $E M B O J$ (2012) 31(8):2047-59. doi:10.1038/emboj.2012.54

72. Brossay L, Chioda M, Burdin N, Koezuka Y, Casorati G, Dellabona P, et al. CD1d-mediated recognition of an alpha-galactosylceramide by natural killer $\mathrm{T}$ cells is highly conserved through mammalian evolution. J Exp Med (1998) 188(8):1521-8. doi:10.1084/jem.188.8.1521

73. Johnson LA, Morgan RA, Dudley ME, Cassard L, Yang JC, Hughes MS, et al. Gene therapy with human and mouse T-cell receptors mediates cancer regression and targets normal tissues expressing cognate antigen. Blood (2009) 114(3):535-46. doi:10.1182/blood-2009-03-211714

74. Gold MC, McLaren JE, Reistetter JA, Smyk-Pearson S, Ladell K, Swarbrick GM, et al. MR1-restricted MAIT cells display ligand discrimination and pathogen selectivity through distinct T cell receptor usage. J Exp Med (2014) 211(8):1601-10. doi:10.1084/jem.20140507
75. Patel O, Kjer-Nielsen L, Le Nours J, Eckle SB, Birkinshaw R, Beddoe T, et al. Recognition of vitamin $\mathrm{B}$ metabolites by mucosal-associated invariant $\mathrm{T}$ cells. Nat Commun (2013) 4:2142. doi:10.1038/ncomms3142

76. Lopez-Sagaseta J, Dulberger CL, Crooks JE, Parks CD, Luoma AM, McFedries $\mathrm{A}$, et al. The molecular basis for mucosal-associated invariant $\mathrm{T}$ cell recognition of MR1 proteins. Proc Natl Acad Sci U S A (2013) 110(19):E1771-8. doi:10.1073/pnas.1222678110

77. Eckle SB, Birkinshaw RW, Kostenko L, Corbett AJ, McWilliam HE, Reantragoon $\mathrm{R}$, et al. A molecular basis underpinning the $\mathrm{T}$ cell receptor heterogeneity of mucosal-associated invariant T cells. J Exp Med (2014) 211(8):1585-600. doi:10.1084/jem.20140484

78. Patel O, Pellicci DG, Gras S, Sandoval-Romero ML, Uldrich AP, Mallevaey $\mathrm{T}$, et al. Recognition of CD1d-sulfatide mediated by a type II natural killer T cell antigen receptor. Nat Immunol (2012) 13(9):857-63. doi:10.1038/ ni.2372

79. Girardi E, Maricic I, Wang J, Mac TT, Iyer P, Kumar V, et al. Type II natural killer $\mathrm{T}$ cells use features of both innate-like and conventional $\mathrm{T}$ cells to recognize sulfatide self antigens. Nat Immunol (2012) 13(9):851-6. doi:10. 1038/ni.2371

80. Roy S, Ly D, Li NS, Altman JD, Piccirilli JA, Moody DB, et al. Molecular basis of mycobacterial lipid antigen presentation by CD1c and its recognition by alphabeta T cells. Proc Natl Acad Sci U S A (2014) 111(43):E4648-57. doi:10.1073/pnas.1408549111

81. Birkinshaw RW, Pellicci DG, Cheng TY, Keller AN, Sandoval-Romero M, Gras $\mathrm{S}$, et al. alphabeta $\mathrm{T}$ cell antigen receptor recognition of $\mathrm{CD} 1 \mathrm{a}$ presenting self lipid ligands. Nat Immunol (2015) 16(3):258-66. doi:10.1038/ni.3098

82. Bai L, Picard D, Anderson B, Chaudhary V, Luoma A, Jabri B, et al. The majority of CD1d-sulfatide-specific $\mathrm{T}$ cells in human blood use a semiinvariant Vdelta1 TCR. Eur J Immunol (2012) 42(9):2505-10. doi:10.1002/eji. 201242531

83. Mangan BA, Dunne MR, O'Reilly VP, Dunne PJ, Exley MA, O'Shea D, et al. Cutting edge: CD1d restriction and Th1/Th2/Th17 cytokine secretion by human Vdelta3 T cells. J Immunol (2013) 191(1):30-4. doi:10.4049/jimmunol. 1300121

84. Spada FM, Grant EP, Peters PJ, Sugita M, Melian A, Leslie DS, et al. Selfrecognition of $\mathrm{CD} 1$ by gamma/delta $\mathrm{T}$ cells: implications for innate immunity. J Exp Med (2000) 191(6):937-48. doi:10.1084/jem.191.6.937

85. Uldrich AP, Le Nours J, Pellicci DG, Gherardin NA, McPherson KG, Lim RT, et al. CD1d-lipid antigen recognition by the gammadelta TCR. Nat Immunol (2013) 14(11):1137-45. doi:10.1038/ni.2713

86. Lee YJ, Holzapfel KL, Zhu J, Jameson SC, Hogquist KA. Steady-state production of IL- 4 modulates immunity in mouse strains and is determined by lineage diversity of iNKT cells. Nat Immunol (2013) 14(11):1146-54. doi:10.1038/ni. 2731

87. Sag D, Krause P, Hedrick CC, Kronenberg M, Wingender G. IL-10-producing NKT10 cells are a distinct regulatory invariant NKT cell subset. J Clin Invest (2014) 124(9):3725-40. doi:10.1172/JCI72308

88. Ly D, Kasmar AG, Cheng TY, de Jong A, Huang S, Roy S, et al. CD1c tetramers detect ex vivo $\mathrm{T}$ cell responses to processed phosphomycoketide antigens. J Exp Med (2013) 210(4):729-41. doi:10.1084/jem.20120624

89. Dusseaux M, Martin E, Serriari N, Peguillet I, Premel V, Louis D, et al. Human MAIT cells are xenobiotic-resistant, tissue-targeted, CD161hi IL-17-secreting T cells. Blood (2011) 117(4):1250-9. doi:10.1182/blood-2010-08-303339

90. Montamat-Sicotte DJ, Millington KA, Willcox CR, Hingley-Wilson S, Hackforth S, Innes J, et al. A mycolic acid-specific CD1-restricted $\mathrm{T}$ cell population contributes to acute and memory immune responses in human tuberculosis infection. J Clin Invest (2011) 121(6):2493-503. doi:10.1172/JCI46216

91. Parekh VV, Wilson MT, Olivares-Villagomez D, Singh AK, Wu L, Wang CR, et al. Glycolipid antigen induces long-term natural killer $\mathrm{T}$ cell anergy in mice. J Clin Invest (2005) 115(9):2572-83. doi:10.1172/JCI24762

92. Butler MO, Hirano N. Human cell-based artificial antigen-presenting cells for cancer immunotherapy. Immunol Rev (2014) 257(1):191-209. doi:10.1111/ imr.12129

93. Butler MO, Ansen S, Tanaka M, Imataki O, Berezovskaya A, Mooney MM, et al. A panel of human cell-based artificial APC enables the expansion of longlived antigen-specific $\mathrm{CD} 4+\mathrm{T}$ cells restricted by prevalent HLA-DR alleles. Int Immunol (2010) 22(11):863-73. doi:10.1093/intimm/dxq440

94. Tanaka M, Butler MO, Ansen S, Imataki O, Berezovskaya A, Nadler LM, et al. Induction of HLA-DP4-restricted anti-survivin Th1 and Th2 responses using 
an artificial antigen-presenting cell. Clin Cancer Res (2011) 17(16):5392-401. doi:10.1158/1078-0432.CCR-10-3083

95. Restifo NP, Dudley ME, Rosenberg SA. Adoptive immunotherapy for cancer: harnessing the T cell response. Nat Rev Immunol (2012) 12(4):269-81. doi:10. 1038/nri3191

96. Crompton JG, Sukumar M, Restifo NP. Uncoupling T-cell expansion from effector differentiation in cell-based immunotherapy. Immunol Rev (2014) 257(1):264-76. doi:10.1111/imr.12135

97. Butler MO, Lee JS, Ansen S, Neuberg D, Hodi FS, Murray AP, et al. Longlived antitumor CD8+ lymphocytes for adoptive therapy generated using an artificial antigen-presenting cell. Clin Cancer Res (2007) 13(6):1857-67. doi:10. 1158/1078-0432.CCR-06-1905

98. Heczey A, Liu D, Tian G, Courtney AN, Wei J, Marinova E, et al. Invariant NKT cells with chimeric antigen receptor provide a novel platform for safe and effective cancer immunotherapy. Blood (2014) 124(18):2824-33. doi:10. 1182/blood-2013-11-541235
99. Hinrichs CS, Rosenberg SA. Exploiting the curative potential of adoptive T-cell therapy for cancer. Immunol Rev (2014) 257(1):56-71. doi:10.1111/imr.12132 100. Richter J, Neparidze N, Zhang L, Nair S, Monesmith T, Sundaram R, et al. Clinical regressions and broad immune activation following combination therapy targeting human NKT cells in myeloma. Blood (2013) 121(3):423-30. doi:10.1182/blood-2012-06-435503

Conflict of Interest Statement: The authors declare that the research was conducted in the absence of any commercial or financial relationships that could be construed as a potential conflict of interest.

Copyright $\odot 2015$ Guo, Chamoto and Hirano. This is an open-access article distributed under the terms of the Creative Commons Attribution License (CC BY). The use, distribution or reproduction in other forums is permitted, provided the original author $(s)$ or licensor are credited and that the original publication in this journal is cited, in accordance with accepted academic practice. No use, distribution or reproduction is permitted which does not comply with these terms. 